\title{
Ansamitomicin P-3
}

National Cancer Institute

\section{Source}

National Cancer Institute. Ansamitomicin P-3. NCI Thesaurus. Code C97710.

An ansamacrolide and maytansine analogue originally isolated from the Ethiopian shrub Maytenus serrata with antineoplastic activity. Ansamitomicin P-3 binds to tubulin at the maytansine-binding site, thereby inhibiting microtubule assembly, inducing microtubule disassembly, and disrupting mitosis. 